\title{
Effects of 8-week zumba exercise on blood lipids profile in sedentary women
}

\author{
Mine Turgut ${ }^{1 \mathrm{ABCD}}$, Yusuf Soylu ${ }^{2 \mathrm{BCDE}}$ \\ ${ }^{1}$ Bartin University, Turkey \\ ${ }^{2}$ Tokat Gaziosmanpasa University, Turkey
}

Authors' Contribution: A - Study design; B - Data collection; C - Statistical analysis; D - Manuscript Preparation; E - Funds Collection.

\begin{tabular}{|c|c|}
\hline \multicolumn{2}{|l|}{ Abstract } \\
\hline Purpose: & $\begin{array}{l}\text { Different aerobic exercise may affect women's health behaviours. Therefore, this study aimed to } \\
\text { determine the effect of 8-week Zumba exercises applied to sedentary women on lipid profile. }\end{array}$ \\
\hline Material: & $\begin{array}{l}\text { Fifty voluntary healthy sedentary women with a mean age of } 32.1 \pm 6.8 \text { years and a mean height of } \\
158.4 \pm 15.5 \mathrm{~cm} \text { participated in the study. Before and after the exercise program, blood samples and } \\
\text { body weight were taken on before breakfast in the morning by experts in the appropriate laboratory } \\
\text { environment, some environmental measurements. In the analysis of the data, the SPSS } 22.0 \text { package } \\
\text { program was used to compare the pre-post exercise values (Paired Sample T-Test) as well as descriptive } \\
\text { statistics. The effect sizes (Cohen's d) were calculated to provide the estimation of the comparisons } \\
\text { between the pre-test and post-test results of the obtained values. }\end{array}$ \\
\hline Results: & $\begin{array}{l}\text { According to the results, it was determined that there were significant differences between blood } \\
\text { lipids Glucose, Urea, Triglyceride, total High-Density Lipoprotein Cholesterol }(\mathrm{HDL}-\mathrm{C}) \text { and Low-Density } \\
\text { Lipoprotein Cholesterol }(\mathrm{LDL}-\mathrm{C}) \text { levels before and after Zumba exercise program }(p<0.05) \text {. In addition, } \\
\text { it was determined that there was a significant and positive change between the pre-test and post-test } \\
\text { BMI values }(p<0.05) \text {. }\end{array}$ \\
\hline Conclusions: & $\begin{array}{l}\text { According to the results of the study, it was concluded that the 8-week Zumba exercise program applied } \\
\text { to sedentary women had a positive effect on the lipid profiles of women. }\end{array}$ \\
\hline Keywords: & zumba, aerobic exercise, blood lipids, physical activity, health \\
\hline
\end{tabular}

\section{Introduction}

Technological development will continue causing inactivity in modern life. Negative effects in inactivity associated with physiological and psychological disorders such as obesity, diabetes, cardiovascular diseases, stress, depression [1-3]. For this reason, people need to recover physically and mental health. According to the World Health Organization, physically active women percentage are decreasing to men in high and low-income countries [4]. It's known that physical activity provides positive effects on psychological and physical health [5, 6]. Therefore, new exercise approaches could be a trigger to women for a more active life.

Many health problems in women such as insulin resistance, total and abdominal visceral fat and intramuscular fat increasing with age [7, 8]. Whereas many researchers determined to many benefits of aerobic exercises improving well-being, cardiovascular, aerobic fitness and lipid profile in women [9, 10]. Despite many benefits of physical active life, people get hard to maintain to exercise in daily routine. Fjeldsoe et al. [11] some factors could be a reason to layover physical activity. Thus, different types of aerobic exercise may be more efficient to maintain exercise and increasing motivation. In the long-term effect exercise on physiological responses can be determined to enjoyment participation. For this reason, Vendramin et al. [12] state that most people will be

(c) Mine Turgut, Yusuf Soylu, 2021

doi:10.15561/26649837.2021.0305 participating like Zumba, Pilates and Spinning exercise. During the last few years, Zumba is one of the new trends in fitness however has plenty of participants in the world [13]. Zumba includes the basics of salsa, samba, cumbia and the basic aerobic steps of other Latin American dances, but also enriches its content with other dances such as hip-hop, belly dance [14-16]. Previous research showed that people who participate in Zumba exercises increasing to enjoyment and motivation $[17,18]$. Besides, Zumba exercises have many positive physiological effects such as body weight, blood lipid levels, some diameter and circumference measurements, providing hormonal balance, and preventing cardiovascular diseases [19]. Sustained more working time with inactive effect on some physical and physiological health, especially in women compared to men in life [20]. In this context, although it's all known that both aerobic and Zumba exercises effect some anthropometric (body mass index, body fat percentage, body weight) and blood lipid profile [10, 12]. There is no study. In the literature how effects on Zumba exercise blood lipid profile in sedentary women. We hypothesized that the Zumba exercise would be beneficial effects on blood lipid profile in sedentary women for a healthy life.

\section{Materials and Method}

Participants

The study was carried out in accordance with the pre-test post-test model. 50 voluntary healthy sedentary 
women with a mean age of $32.1 \pm 6.8$ years and a mean height of $158.4 \pm 15.5 \mathrm{~cm}$ included in the study. Two measurements were taken in the study as pre and posttest. No diet program was applied to the participants. By asking whether the participants have serious illnesses that may affect physical activity and working, the participants who had were not included in the study. The pre-tests of all participants were taken before starting the study, and the post-tests were taken at the end of 8 weeks. During the study, all participants were asked to continue their normal life and not to do extra physical activity during the exercise protocol.

\section{Anthropometric Measurements}

Weight, percentage of fat, and body mass index (BMI) were measured using a bio-impedance-meter scale TANITA BC 532 (Tokyo, Japan). All measurements before breakfast in the morning taken by experts in a suitable environment.

Biochemical Analysis

Blood samples collected before first exercise and at the end of last exercise, determined health institution on before breakfast in the morning by laboratory environment. Blood values; Glucose, Urea, Aspartate Aminotransferase AST, Alanine Aminotransferase (ALT), Triglyceride, Total Cholesterol LDL-C and HDL-C values were obtained by making complete blood counts measurements in Backman Coulter auto analyser.

\section{Exercise Program}

Zumba Fitness Exercise (ZFE) programme lasted 3 days per week in 8 weeks. The Zumba Fitness program was led by a professional Zumba instructor. The Zumba Fitness program took into account the choreographies and class structure of the official Zumba ZIN DVD. Each exercise session starts warm-up of 5-10 minutes including a combination of one or two Latin dance pieces and dynamic stretching. Then women exercised with Zumba figures at $50-60 \%$ of the target heart rate of 60 minutes 6 to 8 tracks in the main section with a combination of different Latin rhythms. (40 to 45 minutes) occurred. Dynamic stretching and breathing techniques for 5 to 10 minutes were used with slow music to calm down [14, 20].

\section{Statistical Analysis}

Descriptive statistics (mean, standard deviation) and paired sample t-test statistical techniques were used in the analysis of the data. The effect sizes (Cohen's d) were calculated in order to estimate the comparisons between pre-test and post-test results. Thresholds for effect size statistics are as follows: $<0.20=$ not important, $0.20-0.59$ $=$ small, $0.6-1.19=$ medium, $1.2-1.99=$ large; $\geq 2.0=$ very large [21]. The level of significance was set at 0.05 and the analyses were carried out on the Windows SPSS 22 program.

\section{Results}

As shown in Table 1, the mean scores of experimental groups are nearly the same, indicating equality of group regarding their knowledge of targeted structures.

The mean age of the sedentary women in the study group was $32.1 \pm 6.9$, the mean of height was $158.4 \pm$ 15.5 , the mean of weight was $86.9 \pm 15.6$, and the mean of was $33.2 \pm 6.3$.

When Table 2 was examined, it was found that the applied Zumba exercise program caused significant changes in the weight and fat percentage values of the participants $(\mathrm{p}<0.05)$.

When Table 3 was examined; It was determined that there was a positive significant difference between the pre-test and post-test values in the blood lipid levels (triglyceride, total cholesterol, HDL-C and LDL-C), Glucose and Urea values of the participants. As can be understood from the results of the analysis, it can be said that the Zumba exercise program applied had a positive effect on the post-test results by decreasing the current values according to the pre-test results of the participants.

Table 1. Physiological characteristics of participants

\begin{tabular}{ll}
\hline Variables & $\overline{\mathbf{x}} \pm$ SD \\
\hline Age $($ year) & $32.1 \pm 6,9$ \\
Weight $(\mathrm{kg})$ & $86.9 \pm 15.6$ \\
Height $(\mathrm{cm})$ & $158.4 \pm 15.5$ \\
$\mathrm{BMI}\left(\mathrm{kg} / \mathrm{m}^{2}\right)$ & $33.2 \pm 6.3$ \\
\hline
\end{tabular}

Table 2. Changes in Weight, BMI before and after 8-weeks Zumba exercise program

\begin{tabular}{|c|c|c|c|c|c|}
\hline \multirow{2}{*}{ Variables } & Pre & Post & \multirow{2}{*}{$\mathbf{p}$} & \multirow{2}{*}{ Cohen $d$} & \multirow{2}{*}{ Magnitude } \\
\hline & $\overline{\mathbf{x}} \pm S D$ & $\overline{\mathbf{x}} \pm \mathrm{SD}$ & & & \\
\hline Weight & $86.9 \pm 15.6$ & $82.9 \pm 15.5$ & $0.000 * *$ & 0.25 & Small \\
\hline Percentage of fat & $41.0 \pm 5.6$ & $34.5 \pm 5.7$ & $0.000 * *$ & 1.15 & Large \\
\hline BMI & $33.6 \pm 6.3$ & $32.3 \pm 6.2$ & $0.000 * *$ & 0.20 & Small \\
\hline
\end{tabular}

$\mathrm{p}<0.05^{* *}$ 
Table 3. Changes in blood lipid before and after 8-weeks Zumba exercise program

\begin{tabular}{|c|c|c|c|c|c|}
\hline \multirow{2}{*}{ Variables } & \multirow{2}{*}{$\begin{array}{l}\text { Pre } \\
\overline{\mathbf{x}} \pm S D\end{array}$} & \multirow{2}{*}{$\begin{array}{l}\text { Post } \\
\overline{\mathbf{x}} \pm S D\end{array}$} & \multirow{2}{*}{$\mathbf{p}$} & \multirow{2}{*}{ Cohen $d$} & \multirow{2}{*}{ Magnitude } \\
\hline & & & & & \\
\hline Glucose $_{(\mathrm{Mg} / \mathrm{dL})}$ & $108.7 \pm 21.8$ & $91.3 \pm 10.1$ & $0.00 *$ & 1.03 & Large \\
\hline Urea & $25.3 \pm 8.0$ & $18.6 \pm 4.9$ & $0.00 *$ & 1.00 & Large \\
\hline Triglyceride $_{(M g / d L)}$ & $135.3 \pm 63.1$ & $81.9 \pm 24.2$ & $0.00 *$ & 1.12 & Large \\
\hline Total Cholesterol $(\mathrm{Mg} / \mathrm{dL})$ & $198.3 \pm 46.4$ & $146.5 \pm 28.2$ & $0.00 *$ & 1.09 & Large \\
\hline $\mathrm{HDL} \mathrm{C}_{(\mathrm{Mg} / \mathrm{dL})}$ & $42.7 \pm 10.3$ & $57.8 \pm 12.4$ & $0.00 *$ & -1.32 & Large \\
\hline $\operatorname{LDL} \mathrm{C}_{(\mathrm{Mg} / d L)}$ & $129.6 \pm 37.2$ & $84.9 \pm 23.9$ & $0.00 *$ & 1.43 & Large \\
\hline
\end{tabular}

$p<0.05^{*}$

\section{Discussion}

The aim of the study is to examine the blood lipid effects of 8-week Zumba exercises on sedentary women. The results of the study showed that aerobic-based Zumba exercises showed significant differences in lipid blood profiles of sedentary women. There have been studies examining the effect of Zumba exercises on weight, body mass index and waist circumference [22-24], $\mathrm{VO}_{2 \max }$ $[25,26]$, and neuromuscular functions [27]. To our knowledge, there were not many studies investigating that Zumba exercises had an effect on blood lipid profiles in sedentary women.

It was known that aerobic exercises had a positive effect on weight loss and body mass index, body anthropometric parameters, and cardiovascular disorders and blood lipid profiles [28-30]. In studies examining the effect of aerobic exercises in middle age women, similar to the current study, aerobic-based exercises were effective in decreasing weight and body mass index [3133]. When the results of this study were examined, it was seen that Zumba exercises caused a significant decrease in glucose level. Previous research also indicated that aerobic exercises reduced blood glucose levels [34-36]. Other studies showing that aerobic exercises reduce glucose levels were found in the literature, but most of these had done on diabetes Type I and II patients. [3740]. There were some differences between the studies that examine the relationship between Zumba and glucose in the literature. In their study on 13 women aged $52.5 \pm$ 10.6 years Araneta and Tanori [41], and Cugusi et al., [22] in their study on 27 sedentary women aged $38.9 \pm 9.7$ years stated that there was no difference between Zumba and glucose. In another study, it was stated that 15 of 30 sedentary female participants with a mean age (45.9 \pm 9.6$)$ actively participated in Zumba exercises for 40 weeks, while there was not attending, no difference in glucose amount after exercise was found [26]. Krishnan et al., [23] stated that Zumba exercises did not reveal a difference in glucose level in 14 healthy women and 14 diabetes type 2 patients with an average age $(49.3 \pm 12.1)$. It can be thought that the difference between the current study and the other studies was due to both the excess in the age range and the different sample groups. In the current study, urea levels also appeared to decrease significantly after the exercise. Huang et al., [42] stated that acute exercise may increase the intensity of urine removal from the body after exercise, however, in previous studies [43, 44], the urea level decreased after exercise. In this study, it can be said that the decrease in urea level may be normal because the urea value was taken after 24 hours.

When the effect of aerobic exercises on the blood lipid profile of sedentary women was examined, it was observed that sedentary women reduced their blood lipid profiles such as cholesterol, triglyceride, HDL-C and LDL-C [32, 34, 44, 45, 46].

In the current study, women who exercised Zumba showed a decrease in triglyceride, cholesterol and LDL-C levels and an increase in HDL-C levels. Krishnan et al., [23] stated that as a result of the 16-week Zumba exercises they applied to women with 14 diabetes and 14 without diabetes, Triglyceride levels decreased in women without diabetes. Similarly, Araneta and Tanori [41] stated that 12-week Zumba exercises decreased Triglyceride and HDL-C levels in women, but not significantly. It was seen in the literature that different exercises had a positive effect on the blood lipid profile of women. Luo and Zheng [47] stated that there was an increase in HDL-C values and a decrease in LDL-C, Triglyceride and total cholesterol levels in 12-week aerobic exercise combined with yoga to 81 female college students. Lee and Kim [48] observed that 16-week yoga exercises increased HDL-C, total cholesterol and triglyceride levels and decreased LDL-C levels in the blood lipid profile of 8 obese women. It posed a serious and fatal risk such as coronary artery disease in people who were physically inactive, and it was emphasized that this disease was associated with high blood lipid and lipoprotein levels [49]. In addition, in studies conducted, blood lipids and lipoproteins appear to be not only the cause of coronary artery diseases but also the cause of many diseases $[30,50]$. Considering that 
aerobic exercises play an effective role in blood lipids and lipoproteins, it can be said that Zumba exercises can also be used as a different type of aerobic exercise.

\section{Conclusion}

The results of this study showed that 8-week Zumba exercises caused changes in weight, BMI and blood lipid profiles of sedentary women. In addition, like other aerobic exercises, Zumba exercises were effective in decreasing body composition and anthropometric characteristics of sedentary women. Considering the importance of the effects of features such as body composition on women in their daily lives, Zumba exercises can be used as a different method compared to classical methods. Another important result of the research was the altering effect of Zumba exercises on blood lipid profiles. It can be said that Zumba exercises were not only affecting body composition in sedentary women but also an important indicator for women to be healthy individuals. In addition, considering that Zumba exercises were a group exercise and music performed with certain rhythms, psychological effects on group dynamics will further increase the quality of the exercise and its effect on women. In future studies, it can be said that the examination of different physiological (such as Hearth Rate, Lactate level) psychological and effects will provide a different benefit to the literature.

\section{Acknowledgements}

This study was written by abridging Mine Turgut and Yusuf Soylu. No grants or financial aids were taken in this Project.

\section{Financial support}

There is no financial support.

\section{Conflict of interest}

The authors declare no conflict of interest

\section{References}

1. DHHS Physical Activity Guidelines Advisory Committee Report. Washington, DC: US Department of Health and Human Services, edited by Services DoHaH; 2008.

2. Laaksonen DE, Lindstrom J, Lakka TA, Eriksson JG, Niskanen L, Wikstrom K, et al. Physical Activity in the Prevention of Type 2 Diabetes: The Finnish Diabetes Prevention Study. Diabetes, 2005;54:158-65. https://doi.org/10.2337/diabetes.54.1.158

3. Shiroma EJ, Lee I-M. Physical Activity and Cardiovascular Health: Lessons Learned From Epidemiological Studies Across Age, Gender, and Race/Ethnicity. Circulation, 2010;122:743-52. https://doi.org/10.1161/CIRCULATIONAHA.109.914721

4. World Health Organization. Physical Activity and Women Fact-Sheet. Available online: https://www.who.int/ dietphysicalactivity/factsheet_women/en/ (accessed on 2 November 2019).

5. Baruth M, Wilcox S, Wegley S, Buchner DM, Ory MG, Phillips A, et al. Changes in Physical Functioning in the Active Living Every Day Program of the Active for Life Initiative ${ }^{\circledR}$. IntJ Behav Med, 2011;18:199-208. https://doi.org/10.1007/s12529-010-9108-7

6. Murrock CJ, Graor CH. Effects of dance on depression, physical function, and disability in underserved adults. $J$ Aging Phys Act. 2014;22(3):380-385. https://doi.org/10.1123/japa.2013-0003

7. Ryan AS, Nicklas BJ. Age-related changes in fat deposition in mid-thigh muscle in women: relationships with metabolic cardiovascular disease risk factors. Int $J$ Obes Relat Metab Disord. 1999; 23:126 - 32. https://doi.org/10.1038/sj.ijo.0800777

8. Goodpaster BH, Thaete FL, Simoneau JA, Kelley DE. Subcutaneous abdominal fat and thigh muscle composition predict insulin sensitivity independently of visceral fat. Diabetes, 1997; 46:1579-85.

9. Donath L, Roth R, Hohn Y, Zahner L, Faude O. The effects of Zumba training on cardiovascular and neuromuscular function infemalecollegestudents.EurJSportSci.2014;14(6):569-577. https://doi.org/10.1080/17461391.2013.866168

10.Arslan E, Can S, Demirkan E. Effect of short-term aerobic and combined training program on body composition, lipids profile and psychological health in premenopausal women. Science \& Sports. 2017:32(2): 106-113. https://doi.org/10.1016/j.scispo.2016.11.004

11.Fjeldsoe B, Neuhaus M, Winkler E, Eakin E. Systematic review of maintenance of behavior change following physical activity and dietary interventions. Health Psychol. 2011;30(1):99-109. https://doi.org/10.1037/a0021974

12.Vendramin B, Bergamin M, Gobbo S, Cugusi L, Duregon F, Bullo V, et al. Health Benefits of Zumba Fitness Training: A Systematic Review. PM\&R, 2016;8:1181-200. https://doi.org/10.1016/j.pmrj.2016.06.010

13.Brenscheidt gen. Jost D. "A Mover la Colita": Zumba Dance-Fitness in Mexico and Beyond. In: de Casanova EM, Jafar A, editors. Bodies Without Borders, New York: Palgrave Macmillan US; 2013. P. 143-61. https://doi.org/10.1057/9781137365385_10

14.Bayraktar A, Kılınç H, Kayantaş İ, Günay M. The effect of 12week regular Zumba exercises on antropometric properties. Journal of Human Sciences, 2020; 17(1): 154- 161. https://doi.org/10.14687/jhs.v17i1.5913

15.Ljubojević A, Jakovljević V, Popržen M. Effects of Zumba fitness program on body composition of women. SportLogia, 2014; 10(1): 29-33. https://doi.org/10.5550/sgia.141001.en.004L

16.Assunção Júnior JC, Almeida Silva HJ, Silva JFC, Silva Cruz R, Almeida Lins CA, Souza MC. Zumba dancing can improve the pain and functional capacity in women with fibromyalgia. J Body w Mov Ther. 2018;22(2):455-459. https://doi.org/10.1016/j.jbmt.2017.09.022

17.Bennett P, Corradini A, Ockerby C, Cossich T. Exercise during hemodialysis the intradialytic Zumba Gold. Nephrol News Issues, 2012; 26:31-32.

18.Krishnan S, Tokar TN, Boylan MM, Griffin K, Feng $\mathrm{D}$, Mcmurry L, et al. Zumba ${ }^{\circledR}$ Dance Improves Health in Overweight/Obese or Type 2 Diabetic Women. Am J Hlth Behav, 2015;39:109-20. https://doi.org/10.5993/AJHB.39.1.12

19.Oge B. A research on the effects of an 8-week zumba and step-aerobics exercise on serum leptin and serum ghrelin hormones in women. [Unpublished Master's Thesis]. Van.; 2019.

20.Barranco-Ruiz Y, Ramírez-Vélez R, Martínez-Amat A, 
Villa-González E. Effect of Two Choreographed Fitness Group-Workouts on the Body Composition, Cardiovascular and Metabolic Health of Sedentary Female Workers. Int J Environ Res Public Health. 2019;16(24):4986. https://doi.org/10.3390/ijerph16244986

21.Hopkins WG, Marshall SW, Batterham AM, Hanin J. Progressive statistics for studies in sports medicine and exercise science. Med Sci Sport Exerc. 2009; 41(1):3- 12. https://doi.org/10.1249/MSS.0b013e31818cb278

22.Cugusi L, Wilson B, Serpe R, et al. Cardiovascular effects, body composition, quality of life and pain after a Zumba fitness program in Italian overweight women. J Sports Med Phys Fitness, 2016; 56(3):328-335.

23.Krishnan S, Tokar TN, Boylan MM, Griffin K, Feng $\mathrm{D}$, Mcmurry L, et al. Zumba ${ }^{\circledR}$ Dance Improves Health in Overweight/Obese or Type 2 Diabetic Women. Am J Hlth Behav, 2015;39:109-20. https://doi.org/10.5993/AJHB.39.1.12

24.MicallefC. The effectiveness of an 8-week Zumba programme for weight reduction in a group of Maltese over weight and obese women. Sport Sci Health, 2014; 10: 211-217. https://doi.org/10.1007/s11332-014-0195-8

25.Rossmeissl A, Lenk S, Hanssen H, Donath L, SchmidtTrucksäss A, Schäfer J. Zum Beat: Evaluation of a Zumba Dance Intervention in Post-menopausal Overweight Women. Sports (Basel), 2016;4(1):5. https://doi.org/10.3390/sports4010005

26.Barene S, Krustrup P, Brekke OL, Holtermann A. Soccer and Zumba as health-promoting activities among female hospital employees: a 40-weeks cluster randomized intervention study. J Sports Sci. 2014;32(16):1539-1549. https://doi.org/10.1080/02640414.2014.906043

27.Donath L, Roth R, Hohn Y, Zahner L, Faude O. The effects of Zumba training on cardiovascular and neuromuscular function infemalecollegestudents.EurJSportSci.2014;14(6):569-577. https://doi.org/10.1080/17461391.2013.866168

28.Dianatinasab A, Koroni R, Bahramian M, BagheriHosseinabadi Z, Vaismoradi M, Fararouei M, et al. The effects of aerobic, resistance, and combined exercises on the plasma irisin levels, HOMA-IR, and lipid profiles in women with metabolic syndrome: A randomized controlled trial. Journal of Exercise Science \& Fitness, 2020;18:168-76. https://doi.org/10.1016/j.jesf.2020.06.004

29.Roffi M, Patrono C, Collet J-P, Mueller C, Valgimigli M, Andreotti F, et al. 2015 ESC Guidelines for the management of acute coronary syndromes in patients presenting without persistent ST-segment elevation: Task Force for the Management of Acute Coronary Syndromes in Patients Presenting without Persistent ST-Segment Elevation of the European Society of Cardiology (ESC). Eur Heart J, 2016;37:267-315. https://doi.org/10.1093/eurheartj/ehv320

30.Church T. Exercise in obesity, metabolic syndrome and diabetes. Prog Cardiovasc Dis, 2011;53(6): 412-4188. https://doi.org/10.1016/j.pcad.2011.03.013

31.Pedersen BK, Saltin B. Evidence for prescribing exercise as therapy in chronic disease. Scand $J \quad$ Med Sci Sports, 2006;16 (Suppl 1):3-63. https://doi.org/10.1111/j.1600-0838.2006.00520.x

32.Rossi FE, Fortaleza AC, Neves LM, Buonani C, Picolo MR, Diniz TA, et al. Combined training (aerobic plus strength) potentiates a reduction in body fat but demonstrates no difference on the lipid profile in post-menopausal women when compared with aerobic training with a similar training load. J Strength Cond Res, 2016;30: 226-234. https://doi.org/10.1519/JSC.0000000000001020
33.Mendonça RMSC, Júnior Araujo AT, Sousa MSC, Fernandes HM. The effects of different exercise programme son female body composition. J Hum Kinet, 2014;43(1): 67-78. https://doi.org/10.2478/hukin-2014-0091

34.Mohr M, Lindenskov A, Holm PM, Nielsen HP, Mortensen $\mathrm{J}$, Weihe $\mathrm{P}$, et al. Football training improves cardiovascular health profile in sedentary, premenopausal hypertensive women. Scand J Med Sci Sports, 2014;24: 36-42. https://doi.org/10.1111/sms.12278

35.MacDonald TL, Pattamaprapanont P, Pathak P, Fernandez $\mathrm{N}$, Freitas EC, Hafida S, et al. Hyperglycaemia is associated with impaired muscle signalling and aerobic adaptation to exercise. Nat Metab, 2020;2:902-17. https://doi.org/10.1038/s42255-020-0240-7

36.Karolkiewicz J, Michalak E, Pospieszna B, DeskurŚmielecka E, Nowak A, Pilaczyńska-Szcześniak, Ł. Response of oxidative stress markers and antioxidant parameters to an 8-week aerobic physical activity program in healthy, post-menopausal women. Archives of Gerontology and Geriatrics, 2009; 49(1): e67-e71. https://doi.org/10.1016/j.archger.2008.09.001

37.Sideravičiūtė S, Gailiūnienė A, Visagurskienė K, Vizbaraitė D. The Effect of Aerobic Exercises on Blood Glucose Concentration in Healthy Girls and Girls with Type 1 Diabetes Mellitus. Baltic Journal of Sport and Health Sciences, 2018;4. https://doi.org/10.33607/bjshs.v4i63.578

38.Tan S, Du P, Zhao W, Pang J, Wang J. Exercise Training at Maximal Fat Oxidation Intensity for Older Women with Type 2 Diabetes. Int J Sports Med. 2018;39(5):374-381. https://doi.org/10.1055/a-0573-1509

39.Dincer S, Altan M, Terzioglu D, et al. Effects of a regular exercise program on biochemical parameters of type 2 diabetes mellitus patients. J Sports Med Phys Fitness, 2016;56(11):1384-1391.

40.Mitranun W, Deerochanawong C, Tanaka H, Suksom D. Continuousvs interval training on glycemic control and macro- and micro vascularre activity in type 2 diabetic patients. Scand J Med Sci Sports, 2014;24(2):e69-e76. https://doi.org/10.1111/sms.12112

41.Araneta MR, Tanori D. Benefits of Zumba Fitness ${ }^{\circledR}$ among sedentary adults with components of the metabolic syndrome: a pilot study. J Sports Med Phys Fitness, 2015;55(10):12271233.

42.Huang M, Lv A, Wang J, Zhang B, Xu N, Zhai Z, et al. The effect of intradialytic combined exercise on hemodialysis efficiency in end-stage renal disease patients: a randomizedcontrolled trial. Int Urol Nephrol, 2020;52:969-76. https://doi.org/10.1007/s11255-020-02459-1

43. Tangvarasittichai S, Lertsinthai $\mathrm{P}$, Taechasubamorn $\mathrm{P}$, Veerapun $\mathrm{O}$, Tang varasittichai $\mathrm{O}$. Effect of moderateintensity exercise training on body weight, serum uricacid, serum hs-CRP, and insulin sensitivity in type 2 diabetic patients. Siriraj Medical Journal, 2017; 61(6), 310-313.

44.Sokal P, Jastrzębski Z, Jaskulska E, Sokal K, Jastrzębska $\mathrm{M}$, Radzimiński $€$, et al. Differences in Blood Urea and Creatinine Concentrations in Earthed and Unearthed Subjects during Cycling Exercise and Recovery. Evidence-Based Complementary and Alternative Medicine, 2013;2013:1-6. https://doi.org/10.1155/2013/382643

45.Hallage T, Krause MP, Haile L, Miculis CP, Nagle EF, Reis RS, et al. The effects of 12 weeks of step aerobics training on functional fitness of elderly women. J Strength Cond Res, 2010;24(8): 2261-2266. https://doi.org/10.1519/JSC.0b013e3181ddacc6

46.Kerksick C, Thomas A, Campbell B, Taylor L, Wilborn C, Mar-cello B, et al. Effects of a popular exercise and weight loss 
program on weight loss, body composition, energy expenditure and health in obese women. NutrMetab, 2009; 6(1): 231-17. https://doi.org/10.1186/1743-7075-6-23

47.Luo J, Zheng B. Effect of yoga combined with aerobic exercise intervention on morphological and blood lipid indicators in female college students. $J$ Sports Med Phys Fitness, 2020;60(3):442-448. https://doi.org/10.23736/S0022-4707.19.10147-8

48.Lee J-A, Kim J-W, Kim D-Y. Effects of yoga exercise on serum adiponectin and metabolic syndrome factors in obese postmenopausal women: Menopause: The Journal of The
North American Menopause Society, 2012;19:296-301. https://doi.org/10.1097/gme.0b013e31822d59a2

49.Gordon B, Chen S, Durstine JL. The effects of exercise training on the traditional lipid profile and beyond. Curr Sports Med Rep. 2014;13(4):253-259. https://doi.org/10.1249/JSR.0000000000000073

50.Vickers KC, Remaley AT. HDL and cholesterol: life after the divorce?. J Lipid Res. 2014;55 (1):4-12. https://doi.org/10.1194/jlr.R035964

\section{Information about the authors:}

Mine Turgut; https://orcid.org/0000-0002-8556-3114; minetrgt@gmail.com; Faculty of Sport Sciences, Bartin University; Bartin, Turkey.

Yusuf Soylu; (Corresponding Author); https://orcid.org/0000-0003-0609-0601; soylusyusuf@gmail.com; Faculty of Sport Sciences, Tokat Gaziosmanpasa University; Tokat, Turkey.

Cite this article as:

Turgut M, Soylu Y. Effects of 8-week zumba exercise on blood lipids profile in sedentary women. Pedagogy of Physical Culture and Sports, 2021;25(3):172-177.

https://doi.org/10.15561/26649837.2021.0305

This is an Open Access article distributed under the terms of the Creative Commons Attribution License, which permits unrestricted use, distribution, and reproduction in any medium, provided the original work is properly cited (http://creativecommons.org/licenses/by/4.0/deed.en).

Received: 10.11 .2020

Accepted: 22.01.2021; Published: 30.06.2021 